\title{
MENGEMBANGKAN PSYCHOLOGICAL STRENGTH PESERTA DIDIK MELALUI BIMBINGAN DAN KONSELING
}

\author{
Nursyamsi \\ Dosen Fakultas Tarbiyah IAIN Imam Bonjol Padang \\ e-mail: e-mail: nursyamsi@yahoo.co.id
}

\begin{abstract}
Counseling is a direct advice to facilitate learners to overcome problems they encounter, and enable them to take the best decision for themselves with full of responsibility. Concept of psychological strength presented in this paper is promoted by Cavanagh (1982). Theorists contend that psychological strength constitutes the power to generate an individual to act in all sphere of his life. The concept of psychological strength consists of three dimensions including: need fulfillment, intrapersonal competencies, and interpersonal competencies. Seffen (2009) defines psychological strength as one's personal quality that is reflected in his ability to respect himself and other people in life, including the ability to make good relationship with friends, family, and other person, together with the ability to carry out interpersonal communication. This personal power can be developed in the process of individual counseling.
\end{abstract}

Key words: psychological strength, personal quality, interpersonal communication

\begin{abstract}
Abstrak: Konseling merupakan teknik bantuan yang secara langsung memfasilitasi peserta didik dalam mengatasi masalah-masalah yang dihadapinya, serta mampu mengambil keputusan yang terbaik untuk dirinya secara bertanggung jawab. Dari kajian berbagai teori, daya psikologis merupakan kekuatan yang mampu menggerakkan setiap orang atau individu untuk berbuat dalam menjalani tuntutan dan kebutuhan hidupnya. Konsep psychological strength ini terdiri dari tiga dimensi, yaitu: need fulfillment, intrapersonal competencies dan interpersonal competencies. Beberapa definisi psychological strength yang dapat disimpulkan maknanya, yaitu bahwa psychological strength atau daya psikologis yang dimiliki oleh setiap individu itu merupakan kualitas dari diri mereka yang terlihat dari kemampuan seseorang menghargai dirinya dan orang lain dalam kehidupan, termasuk kemampuan menjalin hubungan baik dengan sahabat, keluarga, dan orang lain, atau kemampuan melakukan komunikasi antarpribadi. Daya psikologis ini dapat dikembangkan dalam proses konseling pada individu (peserta didik) oleh konselor.
\end{abstract}

Kata Kunci: daya psikologis, kualitas dari diri, komunikasi antarpribadi

\section{PENDAHULUAN}

Cavanagh, M. (1982: 33) menjelaskan bahwa daya psikologis merupakan suatu kekuatan yang diperlukan oleh individu untuk menghadapi berbagai tantangan dalam keseluruhan hidup, termasuk menyelesaikan berbagai masalah yang dihadapinya. Pada dasarnya daya psikologis adalah kekuatan yang menggerakkan individu untuk berbuat dalam menjalani tuntutan keseluruhan hidupnya. M. Surya (2003: 45) mengemukakan bahwa berkaitan dalam hubungan ini, para konselor perlu memahami konsep "psychological strength" sebagai landasan dalam memahami kehadiran konseli dalam konseling.
Clarissa Steffen. (2009) mengemukakan beberapa definisi tentang psychological strength sebagai berikut:

Psychological qualities can appear nebulous if you haven't clearly defined what you are looking for in yourself or others. We can readily determine physical strength and place a lot of value on athletes who posses this quality. We can see psychological strength in a person who has done a courageous actbut how do we define it in the everyday common man? This is a little more difficult, because the quality of psychological strength is poorly defined. Let's explore some aspects of strength as it applies to psychological behavior. Understanding psychological strength 
may help you better appreciate yourself and others.

Possessing pride, dignity, and a healthy self-image are psychological strengths to pursue in life. Finding these qualities in yourself and others can bring your life into balance. We all have individual differences, and the diversity brings richness to life. Knowing a person by the choices they make can tell you more than words can ever speak!

Relationships, friends and families can reveal a lot about a person. If they value relationships, and treat them with respect and dignity they will likely treat themselves and others with respect and dignity. It is life experiences that are the fiber of a person, and how they connect to life provides strength!

Having the ability to ask for help and receive help is an overlooked strength. Many people perceive asking for help as a weakness. They underestimate the value in humility, and the value of being able to connect to other human beings in our most human form with all our imperfections. It takes strength to admit we are imperfect, and courage to reveal it to others. There in lies real strength!

Respecting where we come from, cultural values, and our communities can be a real source of strength. Participating in activities whether they are practical, athletic or creative can provide us with an opportunity to develop psychological strength. Remembering where we come from, revisiting if we have left it in life, or treasuring it is we have remained offers ample opportunity to experience psychological strength and develop it as part of our character.

Dalam beberapa definisi psychological strength yang dikemukakan oleh Clarissa Steffen di atas dapat diambil kesimpulan bahwa psychological strength adalah kualitas diri individu yang terlihat dari kemampuan menghargai dirinya dan orang lain dalam kehidupan, termasuk juga kemampuan seseorang menjalin hubungan baik dengan sahabat, keluarga, dan orang lain, atau kemampuan melakukan komunikasi antarpribadi (interpersonal competencies). Sebagian besar komunikasi antar-manusia dilakukan melalui komunikasi interpersonal.

Selanjutnya Cavanagh, (2002:192) menjelaskan bahwa psychological strength itu diperlukan oleh seseorang dalam menghadapi berbagai tekanan dalam hidup sebagai berikut.

Human beings are subject to a variety of physical and psychological needs. Fulfilling these needs is essential because the more healthy needs people meet, the more psychological strength they come to possess. And the more psychological strength people have, the more they handle stress constructively and behave in ways that ultimately bring them realistic amounts of satisfaction and happiness. Conversely, the less psychological strength people possess the more ineffectual they are in the face of stress and the more dissatisfaction and distress they experience.

Apa yang dikemukakan Cavanagh di atas dapat dipahami bahwa orang yang memiliki daya psikologis yang kuat mampu menghadapi tekanan-tekanan dalam hidup, dan mampu menyelesaikan konflik secara efektif sehingga menemukan kebahagiaan. Sebaliknya orang yang kurang memiliki daya psikologis tidak efektif menghadapi stress dan tidak merasakan kebahagiaan dalam hidup.

M. Surya (2003: 45) mengemukakan bahwa psychological strength pada dasarnya merupakan suatu kekuatan yang menggerakkan individu untuk berbuat dalam menjalani tuntutan keseluruhan hidupnya, termasuk menyelesaikan berbagai masalah yang dihadapinya.

Tingkat daya psikologis yang dimiliki oleh setiap individu berbeda-beda, dan ini akan mempengaruhi kualitas hidup mereka sebagaimana dikemukakan oleh Cavanagh (2002:191) berikut ini:

In general, level of psychological strength profoundly influence the quality of one's life ; deficiencies often cause 
people to expereience greater than necessary amounts of dissatisfaction and distress in their lives and, in many casesm to seek counseling. Since psychological strength profoundly effects how people respond to challenging or traumatic events, clients are often aware of the need for greater Strength in order to resolve the important issues in their lives.

\section{PEMBAHASAN}

ASPEK-ASPEK PSYCHOLOGICAL STRENGTH

Model psychological strength atau daya psikologis ini terdiri dari tiga dimensi yang saling berkaitan antara satu dimensi dengan dimensi yang lain pada diri individu. Adapun dimensi-dimensi tersebut adalah sebagai berikut:

\section{Need Fulfillment (Pemenuhan Kebu- tuhan)}

Aspek ini merupakan suatu kekuatan psikis yang harus dimiliki oleh individu agar dia dapat memenuhi tuntutan kebutuhan hidup untuk mencapai kebahagiaan hidup. Jika individu makin banyak memiliki daya psikologis pada aspek ini, maka dapat diprediksi individu ini mampu memenuhi tuntutan kebutuhan hidupnya sehingga dai dapat menikmati hidup dengan sukses dan bahagia. Namun sebaliknya, jika sedikit psikologis pada aspek ini yang dimiliki oleh individu, maka peluang dia akan menghadapi berbagai masalah dalam hidupnya yang dapat menimbulkan frustasi dan hidup yang tidak efektif.

Dalam aspek need fulfillment, ada beberapa kebutuhan yang dibutuhkan oleh setiap orang atau individu dalam hidupnya, dan kemampuan orang yang berbeda-beda dalam memenuhi tuntutan kebutuhan pada aspek ini, kebanyakan individu mengalami kesulitan untuk memenuhi kebutuhan ini. Adapun kebutuhankebutuhan pada aspek ini adalah sebagai berikut:

a. Giving and Receiving Affection (Memberi dan Menerima Kasih Sayang)

b. Beeing Free (Kebebasan)

c. Play (Memiliki Kesenangan)

d. Receiving Stimulation (Menerima Stimulasi)

e. Feeling a Sense of Accomplishment (Perasaan Mencapai Prestasi)

f. Having Hope (Memiliki Harapan) g. Having Solitude (Memiliki Ketenangan)

h. Having an Existential Pupose in Live (Memiliki Tujuan Hidup Yang Jelas)

\section{Intrapersonal Competencies (Kompetensi Intrapersonal)}

Aspek kedua dari psychological strength adalah kompetensi intrapersonal. Kompetensi ini berkaitan dengan kemampuan individu memahami diri sendiri, dan berhubungan dengan diri pribadi. Jika individu mampu berhubungan dengan dirinya secara baik, maka akan baik pula dia berhubungan dengan orang lain, dan sebaliknya. Kompetensi intrapersonal ini berkaitan dengan konsep diri seseorang, yaitu pandangan individu tentang dirinya sendiri. Kompetensi intrapersonal ini terdiri dari tiga kompetensi, yaitu :
a. Self-Knowledge (Pengetahuan diri)
b. Self-Direction (Pengarahan Diri)
c. Self-Esteem (Harga Diri)

\section{Interpersonal Competencies (Kompetensi Antarpribadi)}

Aspek ketiga dari psychological strength merupakan kompetensi antarpribadi, yaitu kekuatan psikis yang berkaitan dengan hubungan bersama orang lain dalam kehidupan dan interaksi dengan lingkungan. Kompetensi interpersonal ini bertindak sebagai jembatan yang menghubungkan individu dengan dunia luar. Makin kuat jembatan ini, makin efektif individu membangun hubungan dengan orang lain, dan akan mencapai kepuasan hidup. Sebaliknya, makin kecil daya psikologis ini pada individu makin besar kemungkinan menghadapi berbagai masalah dan kendala dalam berinteraksi dengan orang lain, sehingga hidup tidak nyaman.

Ada beberapa dimensi yang berkaitan dengan kurangnya kompetensi antarpribadi pada individu sebagai berikut :

a. Sensitivity to Oneself and Others (Kepekaan terhadap Diri Sendiri dan Orang Lain)

b. Assertiveness (Ketegasan Diri)

c. Being Comfortable with Oneself and Others (Menjadi Nyaman dengan Diri Sendiri dan Orang Lain)

d. Allowing Others to be Free (Menjadi Diri yang Bebas) 
e. Realistic Expectations of Oneself and Others. (Harapan yang Realistik Terhadap Diri Sendiri dan Orang Lain).

f. Self-Protection in Interpersonal Situations (Perlindungan Diri dalam Situasi Antarpribadi)

Ketiga dimensi psychological strength di atas saling berkaitan antara satu dimensi dengan dimensi lain pada diri individu. Artinya ketika terjadi perubahan dalam satu dimensi menjadi lebih baik atau lebih buruk, maka akan menyebabkan perubahan pada dimensi yang lain. ( M. Surya, 2003: 45).

Contoh saling keterkaitan antara satu aspek dengan aspek yang lain adalah jika individu kurang daya psikologis pada aspek kompetensi intrapribadi, kurang mampu mengarahkan diri sendiri (self-direction), dan akan dimanifestasikan dalam sikapnya kurang percaya diri serta kurang mampu mengendalikan diri. Maka akan berdampak juga pada aspek antarpribadi seperti tidak tegas dalam bertindak bila berinteraksi dengan orang lain, artinya individu ini tidak mampu mengkespresikan hak-hak pribadinya secara lebih tegas dan efektif. Dampak lain pada aspek (need fulfillment) yaitu pemenuhan kebutuhan akan mengurangi kebebasan dalam bertindak untuk mengambil keputusan dari diri sendiri.

Tugas konselor dalam konseling adalah untuk memperkuat ketiga aspek daya psikologis klien tersebut (psychological strength) sehingga masing-masing daya psikologis ini dapat berkembang pada diri individu secara optimal.

BIMBINGAN DAN KONSELING SEBAGAI BANTUAN DALAM MENGEMBANGKAN PSYCHOLOGICAL STRENGTH PESERTA DIDIK

\section{Makna Bimbingan di Sekolah}

Bimbingan adalah sistem yang komprehensif yang meliputi fungsi, pelayanan, dan program di sekolah yang didesain untuk membantu perkembangan pribadi dan kompetensi psikologis peserta didik. Sebagai konsep pendidikan, bimbingan merupakan serangkaian perencanaan pengalaman bagi siswa yang didesain untuk meningkatkan perkembangan dan outcome pendidikan. Furqon, 2005: 4).
Bimbingan adalah proses membantu individu memahami diri dan dunianya, dan dalam konteks pendidikan bimbingan terfokus kepada pengembangan lingkungan belajar yang dapat memfasilitasi individu memperoleh kesuksesan belajar. (Sunaryo Kartadinata, 2011: 254).

\section{Makna Konseling}

Konseling adalah proses pemberian bantuan yang dilakukan melalui wawancara dan teknik-teknik pengubahan tingkah laku lainnya oleh seorang ahli (konselor) kepada individu atau individu-individu yang sedang bermasalah (klien), yang bermuara pada teratasinya masalah yang dihadapi klien. (Abimanyu \& Manrihu. 1996: 12).

Konseling adalah upaya bantuan yang diberikan seorang pembimbing yang terlatih dan berpengalaman, terhadap individu-individu yang membutuhkanm agar individu tersebut berkembang potensinya secara optimal, mampu mengatasi masalahnya, dan mampu menyesuaikan diri terhadap lingkungan yang selalu berubah. (Sofyan S. Wilis. 2004: 18)

Dari makna bimbingan dan konseling di atas dapat dipahami bahwa dua terminologi dirangkaikan sebagai satu keutuhan layanan ahli dalam hal mana konseling merupakan tenik bantuan yang secara langsung memfasilitasi konseli (peserta didik) dalam mengatasi masalah dan mengambil keputusan secara konstruktif, sementara bimbingan mengandung ragam teknik yang lebih bersifat pedagogis untuk menfasilitasi perkembangan konseli dalam upaya mengembangkan perilaku-perilaku jangka panjang secara sehat dan mengembangkan lingkungan perkembangan yang membuka akses luas kepada konseli, jelasnya peserta didik, untuk memperoleh sukses di dalam belajar. Abimanyu \& Manrihu. 1996: 23).

Dari penjelasan-penjelasan di atas dapat ditarik makna bahwa bimbingan pada dasarnya adalah proses membantu individu (peserta didik) agar mereka dapat membantu diri sendiri dalam menyelesaikan masalah yang dihadapinya. (A. Juntika Nurihsan, 2007: 9). Bimbingan lebih mengarah untuk memberikan petunjuk dan nasehat kepada peserta didik (klien). Konseling 
berbeda dengan membimbing, konseling memberikan peluang kepada klien untuk mengungkapkan apa yang sedang dia alami dan apa yang ia inginkan, sehingga dapat mengurangi beban pemikiran dan perasaannya. Sehingga konselor dapat membantu klien agar lebih menyadari dimana diri klien berada dan apa yang ia inginkan dalam dirinya.

Jadi dalam proses konseling, konselor berusaha untuk membantu klien dalam mengembangkan dirinya sesuai dengan nilainilai pribadi dan nilai-nilai masayarakat di sekitarnya. Artinya, bagaimana potensi yang ada pada diri klien dapat dimunculkan, sehingga klien dapat dan mampu serta memahami masalah yang sedang dihadapinya, dan klienlah yang akan menyelesaikan masalahnya sendiri. Karena pada dasarnya manusia adalah baik, maka dalam proses konseling berusaha untuk mengembalikan klien kepada potensi dasarnya. Sehingga dapat mengembangkan potensi dirinya dalam kehidupan dan menemukan jati dirinya. (Abubakar Baraja, 2008: 40).

Sesuai dengan tujuan yang ingin dicapai dalam konseling adalah agar konseli; (a) memperoleh pemahaman yang lebih baik terhadap dirinya, (b) mengarahkan dirinya sesuai dnegan potensi dirinya ke arah tingkat perkembangan yang optimal, (c) mampu memecahkan sendiri masalah yang dihadapinya, (d) mempunyai wawasan yang lebih realistis serta penerimaan yang objektif tentang dirinya, (e) memperoleh kebahagiaan dalam hidupnya dan dapat menyesuaikan diri secara lebih efektif baik terhadap dirinya sendiri maupun terhadap lingkungan, (f) mencapai taraf aktualisasi diri sesuai dengan potensi yang dimilikinya, (g) terhindar dari gejala-gejala kecemasan dan salah suai (maladjustment). (A. Juntika Nurihsan, 2007: 10).

Tugas konselor adalah memperkuat "Psychological Strength" atau daya psikologis peserta didik pada tiga dimensi, yaitu: need fulfillment (pemenuhan kebutuhan), intrapersonal competencies (kompetensi intrapribadi) dan interpersonal competencies (Kompetensi Antarpribadi), sehingga saling terkait satu dimensi dengan yang lainnya, kemudian dapat saling memperkuat derajat fungsi daya psikis secara keseluruhan. Pada saat terjadi peningkatan kompetensi intrapribadi dan antarpribadi, terjadi pula peningkatan pemuasan kebutuhan, terjadi peningkatan daya psikologis yang kemudian menentukan derajat fungsi psikologis secara keseluruhan. (A. Juntika Nurihsan, 2007: 47).

\section{SIMPULAN}

Berdasarkan pembahasan di atas, dapat diambil beberapa kesimpulan sebagai berikut:

1. Kemampuan seseorang atau individu dalam menghadapi berbagai tantangan, rintangan, kesulitan serta kemampuan menyelesaikan masalah yang dihadapinya dalam hidup ditentukan oleh kekuatan daya psikologis yang dimilikinya, menurut teori yang dikemukakan oleh Michael E. Cavanagh.

2. Daya psikologis atau psychological strength, yang dimiliki oleh setiap individu berbedabeda, dan biasanya orang atau individu maupun peserta didik yang datang ke konselor untuk konseling pada dasarnya karena kekurangan daya psikologis atau psychological strength.

3. Psychological strength pada individu dapat dikembangkan melalui proses konseling. Konselor membantu individu (klien) melalui arahan yang tepat. Konselor dapat membantu diri klien berada, dan dimana dia ingin berada.

\section{DAFTAR RUJUKAN}

A. Juntika Nurihsan. 2007. Bimbingan \& Konseling dalam berbagai latar Belakang kehidupan. Bandung:Rafika Aditama.

Abimanyu \& Manrihu. 1996. Tehnik dan Laboratorium Konseling, Jakarta: Depdikbud Dirjen Dikti.

Abubakar Baraja. 2008. Psikologi dan Teknik Konseling. Jakarta:Studia Press.

Cavanagh \& Levitov. 2002. The Counseling Experience A Theoritical and Practical Approach. USA : Waveland Press Inc.

Cavangh. Michael, E. 1982. The Counseling Experience A Theoritical and Practical Approach. Monterey California: Brook/ Cole Publishing Company. 
Clarissa Steffen. 2009. Define Psychological Sunaryo Kartadinata. 2011. Menguak Tabir Strength.

http://www.ehow.com/how_2180222_ definepsychological-strength.html Bimbingan dan Bimbingan dan Konseling Sebagai Upaya Pedagogis. Bandung:UPI Press.

Furqon. 2005. Konsep dan Aplikasi Bimbingan Konseling di Sekolah Dasar. Bandung: Pustaka Bumi Quraisy.

M. Surya. Psikologi Konseling. 2003. Bandung: Pustaka Bani Quraisy

Sofyan S. Wilis. (2004). Konseling Individual Teori dan Praktek. Bandung:Alfabeta. 